CESIS Electronic Working Paper Series

Paper No. 276

\title{
Knowledge flows, knowledge externalities and regional economic development
}

\author{
Charlie Karlsson \\ Urban Gråsjö
}

June 1 


\title{
Knowledge flows, knowledge externalities and regional economic development
}

\author{
Charlie Karlsson \\ Jönköping International Business School \\ Jönköping, Sweden \\ charlie.karlsson@jibs.hi.se \\ Urban Gråsjö \\ University West \\ Trollhättan, Sweden \\ urban.grasjo@hv.se
}

\begin{abstract}
New knowledge generated by an economic agent in a region will tend over time to flow to other economic agents in the same region but also to economic agents in other regions. It is quite common in the literature to use the concept of knowledge spillovers for such knowledge flows, irrespective of whether they are intended or non-intended. The potential for intra-regional knowledge spillover effects depends on the volume and character of the generation on new knowledge in each region as well as of the general characteristics of the individual regional economic milieu, i.e., those location attributes, which are regionally trapped and which include how well integrated it is with other regions. The larger this potential, the higher the probability that firms dependent upon knowledge spillovers will locate there and the higher probability that entrepreneurs will take advantage of this potential to launch innovations and to create new knowledge-based firms. To the extent that firms and entrepreneurs can enjoy these knowledge spillovers, they represent an externality or more specifically a knowledge externality in the regional economy.

Great importance is in the literature attributed to knowledge spillovers and knowledge externalities as drivers of regional economic development. Some authors, for example, claim that regional variations in localised knowledge spillovers are one of the main reasons behind regional variations in innovation performance. Against this background, the purpose of this chapter is, based upon a general characterization of knowledge flows, to analyse the character of knowledge externalities and, in particular, their sources, their economic nature, their recipients, their mechanisms and channels, their geographic reach, and their economic consequences generally and for regional economic development in particular.
\end{abstract}

Keywords: Knowledge flows, Knowledge externalities, Knowledge spillovers, Regional growth

JEL-codes: O18, R11, R12 


\section{Introduction}

According to the new endogenous growth theory, cumulative processes characterized by either self-reinforcing decline or self-reinforcing growth drive regional economic development, which may last for long periods and which transform location patterns considerably. Knowledge accumulation is here a crucial factor for generating sustained regional economic growth. In the different functional regions, such dynamics are recognized as change processes involving location and migration of firms and households. Thus, a significant part of regional economic growth can be modelled as induced by changes in knowledge, technology, organization and location, which are related to regional scale effects and durable, i.e. slowly changing, regional characteristics. In particular, models of endogenous growth normally treat knowledge capital as an independent production factor, which, however, partly has the character of a public good. Hence, part of the new knowledge generated by an economic agent in a region will tend over time to flow to other economic agents in the same region but also to economic agents in other regions. It is quite common in the literature to use the concept of knowledge spillovers for such knowledge flows, irrespective of whether they are intended or non-intended. A number of studies also provide evidence of the contribution of "knowledge spillovers" to economic growth. However, these studies have clear weaknesses. They, for example, do not clarify the mechanisms and channels through which knowledge spills over, i.e. flows, and they assume that all economic agents equally benefit from the spillovers. However, to understand how knowledge flows effect regional economic growth, and how regional policies can influence regional economic growth via measures that effect knowledge flows, we need to understand the role and function of different mechanisms and channels for knowledge flows, i.e. we must apply a micro-economic perspective.

Knowledge can flow between economic agents in the form of i) a knowledge transaction, where economic agents, for example, purchases a patent, ii) as a by-product in connection with normal purchases of goods and services and/or iii) through other interaction between economic agents or their employees. When the knowledge flows are not fully compensated, we talk about knowledge spillovers. Griliches (1992) defined knowledge spillovers as 'working on similar things and hence benefiting much from each other's research' but it is important to stress here that we here do not restrict knowledge spillovers only to occur in connection with research, since knowledge also can be generated in other ways, such as 'learning-bydoing'.

Intra-regional knowledge spillovers, i.e. localised knowledge spillovers, may generate dynamically increasing returns in the regional economy and, thus, stimulate innovation and regional economic growth. Such increasing returns have long-term effects, since they create a tendency for any given ranking of the competitive positions of regions to persist over time. The potential for intra-regional knowledge spillover effects is a function of the volume and character of the generation on new knowledge in each region as well as of the general characteristics of the individual regional economic milieu, i.e., those location attributes, which are regionally trapped and which include how well integrated it is with other regions. The larger this potential, the higher the probability that firms dependent upon knowledge spillovers will locate there and the higher probability that entrepreneurs will take advantage of this potential to launch innovations and to create new knowledge-based firms. To the extent that firms and entrepreneurs can enjoy these knowledge spillovers, they represent an externality or more specifically a knowledge externality in the regional economy.

Great importance is in the literature attributed to knowledge spillovers and knowledge externalities as drivers of regional economic development. Some authors, for example, claim that 
regional variations in localised knowledge spillovers are one of the main reasons behind regional variations in innovation performance (Jaffe, Trajtenberg \& Henderson, 1993). Against this background, the purpose of this chapter is, based upon a general characterization of knowledge flows, to analyse the character of knowledge externalities and, in particular, their sources, their economic nature, their recipients, their mechanisms and channels, their geographic reach, and their economic consequences generally and for regional economic development in particular (cf. Johansson, 2005).

This chapter is organized as follows: In Section 2 we discuss the nature of knowledge and its effect on the economy. Knowledge flows are discussed in Section 3. Section 4 highlights aspects of knowledge externalities including their economic nature, the sources of knowledge externalities, the recipients of knowledge externalities, the mechanisms and channels of knowledge spillovers, the geographic reach of knowledge spillovers and the consequences of knowledge spillovers. The relationships between knowledge externalities and regional economic development are discussed in Section 5, which is followed up in Section 6 with a discussion of policy conclusions. Section 7 concludes.

\section{The nature of knowledge}

In order to discuss knowledge flows and the knowledge spillovers and externalities they may generate, we must first discuss the nature of knowledge and its effects on the economy. A natural starting point is to examine how to distinguish between information and knowledge. Information can be defined as messages or data, which can easily be codified and therefore transmitted, received, transferred and stored at low costs. Of course, these messages can communicate statements about knowledge. Knowledge, on the other hand, consists of organised or structured information that is difficult to codify and interpret and thus to transform into useful messages, generally due to its intrinsic complexity and indivisibility. Thus, much knowledge is tacit because it is the cumulative output of long periods of learning, specific to a particular setting, and cannot easily be written down and become codified.

Focusing on knowledge that can be related to the activities of economic agents, we can distinguish between the following categories:

- Know-how, which is always embodied in persons or embedded in economic agents, such as firms and other organizations. It signifies expertise, skills and practical attainments. Know-how can be present without codified instructions, generically based on experience and training and often so difficult (or uneconomical) to codify that it remains tacit.

- Know-why, which has the character of systematic and broadly accepted (scientific) explanations, which can be stored in codified form, but which may require specific training and skills to be decoded and understood. It refers to a capacity to understand and explain. Know-why refers to science in the sense that it does not exist - by definition - if it has not been created and codified.

- Knowledge in the form of human capital, which represents a combination of knowhow and know-why embodied in persons.

- Knowledge embodied in products (hardware and software) created by persons or economic agents by applying human capital, know-why and know-how in some production process. 
For knowledge spillovers and related externalities, it is essential to consider the degree to which knowledge is 'rivalrous' and 'excludable' (cf. Cornes \& Sandler, 1986). A rival good has the property that its use by one economic agent precludes the use by another economic actor, whereas a non-rival good lacks this property. Excludability relates to both technology and legal systems. A good is excludable if the owner can prevent others from using it. Pure public goods are both non-rival and non-excludable. This creates a fundamental conflict in society, since an economic agent will only be motivated to carry out R\&D if competitors can be excluded, whereas society will benefit if the knowledge (innovation) is allowed to diffuse to be used by many economic agents (cf. Arrow, 1962).

What types of knowledge are then relevant from the perspective of an economic agent? The following primary types of knowledge can be considered:

- Knowledge about activity routines;

- Knowledge about output varieties;

- Knowledge about markets and customers' willingness to pay for different output varieties;

- Knowledge about routines to develop activities and output development activities.

Activity routines include techniques, methods and approaches that to a varying extent are applied in production, administration, distribution, logistics, transaction, interaction activities, and for innovative economic agents also activity and output development activities including general search for new knowledge (cf. Nelson \& Winter, 1982). The routines are a manifestation of the know-how of an economic agent. From a related perspective, it is possible to identify the following three knowledge concepts: i) scientific knowledge (principles), ii) technological knowledge (blueprints), and iii) entrepreneurial (business) knowledge. In this context, it seems important to remark that both scientists and engineers perform $R \& D$ activities, while making use of know-how about effective and feasible ways to conduct research. Attempts to codify such know-how are often quite primitive and superficial.

However, whatever knowledge concept we use, it is important to observe that knowledge is distributed across a large number of individuals and other economic agents in every economy and that this distributed knowledge must be combined in new ways to generate new knowledge and innovations. Thus, to generate new knowledge economic agents are dependent upon both "inside" and "outside" knowledge, where the former refers to an economic agent's own investments in new knowledge, such as $R \& D$, whereas the latter refers to knowledge production activities performed by other economic agents. Own investments in knowledge production can from this perspective be comprehended as means to absorb and appropriate "outside" knowledge (Cohen \& Levinthal, 1989). This absorptive capacity is also a function of the employment of skilled and highly educated individuals by economic agents, since the presence of such employees seems to be a key channel by which knowledge is transmitted across economic agents.

Understanding how combinations of distributed knowledge generate new knowledge, demands interactive models of knowledge creation and innovation, which can be achieved within national, regional and metropolitan systems of innovation. This implies that new knowledge is not created in some anonymous knowledge production process. Instead, new knowledge is the result of interaction between often-identifiable individuals, who previously have accumulated a substantial stock of knowledge in their specific fields of expertise but who also more or less constantly are keeping themselves updated through various knowledge 
channels to be aware of new knowledge created elsewhere. New knowledge is created when these individuals share their knowledge within a larger group of people, e.g. at a university department or in a research institute or in the research department of an economic agent.

Once it is recognized that new knowledge and new ideas are often off springs, variations or combinations of existing knowledge, the significance of "outside" knowledge becomes clear. As knowledge as an input in knowledge production is non-rival and tends to diffuse and spillover despite various appropriability mechanisms, it is frequently maintained that there are increasing returns in knowledge production. For such returns to emerge diffusion and spillovers of the accumulated and, in particular, the newly generated knowledge is central, as it must be accessible for other economic agents as an input in their knowledge production. However, we must acknowledge that knowledge is often extremely complicated and contains complex elements. This implies that it often only is accessible via interactions within either the economic agents' innovation networks or general innovation systems that according to much of the literature in the field tend to be bounded by geographical proximity (Jaffe, Trajtenberg \& Henderson, 1993; Karlsson \& Manduchi, 2001).

\section{Knowledge flows}

Knowledge flows can be described as a special sort of communication related to the diffusion of messages, products, individuals or economic agents that embody new ideas, knowledge, concepts, blueprints, and so on (Rogers, 1983). Such flows occur whenever an idea generated by a certain economic agent is learned by another economic agent, and indicate a process where economic agents learn from another economic agent's ideas and combine these with internally generated ideas and internally existing ideas, thereby developing and extending the internally existing stock of ideas (cf. Griliches, 1992). However, this learning can occur through many different mechanisms, such as markets, publications, social networks, professional networks, education and training and labour mobility, which indicates that the diffusion of knowledge is a complex matter to disentangle and to understand not least since it is also dependent upon formal and informal institutions and the level of social capital (Helpman, 2008 , Ed.). Concerns have been raised that, on the one hand, the role of knowledge diffusion is underestimated, and that, on the other hand, the role of knowledge spillovers, i.e., unpriced knowledge externalities, compared to normal market transactions of knowledge is overestimated in economic theory (Breschi \& Lissoni, 2001).

As the creation of knowledge is spatially concentrated it is obvious that knowledge flows that diffuse knowledge spatially play a decisive role in regional economic development. Due to its character, a substantial part of the diffusion of more complex knowledge takes place through face-to-face interaction. Frequent face-to-face interaction brings distinct information including persistent updates, planned and unplanned learning and the development of similar interpretation schemes, shared understanding of new knowledge and technologies, local institutions and similar cultural traditions and habits. Developments within "cognitive science" have since several decades credited processes of face-to-face interaction a fundamentally important role for knowledge accumulation and knowledge generation among economic agents. Spatial proximity facilitates face-to-face interaction, and, thus, tends to accelerate the transfer of knowledge between individuals and other economic agents. However, spatial proximity is not a sufficient condition for knowledge transfers to take place. Learning often requires trust and cognitive and social proximity, which of course may be facilitated by spatial proximity. 
There is actually a long tradition in economics studying these knowledge flows in terms of knowledge diffusion and knowledge spillovers. However, it is in particular since pioneering work of Griliches (1992) that knowledge flows have been extensively analysed in the microproductivity literature but also in a growing literature on knowledge spillovers in a spatial context.

The study of knowledge flows has used a number of distinct approaches and techniques. What can be characterised as a technological approach has assumed that knowledge only flows between economic agents (firms) in the same technology group. Other studies use more innovatory measures of knowledge flows and define, for example, technological distance as a bilateral measure, which permits different flow intensities between different pairs of economic agents (Jaffe, 1986).

Since the early 1990s, researchers have increasingly used patent citations to follow the path of learning. Patent citations in fact report the potential learning flows between the citing and the cited economic agent. The importance of distance for knowledge flows has been tested by means of patent data (Jaffe, Trajtenberg \& Henderson, 1993). Patent data has also been used for analysing and comparing knowledge flows originating in universities, federal labs and firms (Jaffe, 1989).

\section{Aspects of spatial knowledge externalities}

Knowledge externalities can occur in situations where the protection of proprietary knowledge is incomplete. To be able to disentangle the role of knowledge externalities in regional economic development we need to distinguish between six aspects of knowledge externalities: i) their economic nature, ii) their sources, iii) their recipients, iv) their mechanisms, v) their geographical reach, and vi) their effects (cf. Johansson, 2005). Knowledge externalities involve firms but also other types of organization and to have a more general discussion we use the more general term economic agents. Economic agents are characterised by two main types of activities:

- Ordinary production activities, i.e., at each point in time an economic agent uses current and fixed inputs to produce output by means of given techniques (routines), and

- Development activities, i.e. the use by economic agents of part of the inputs to develop new types of outputs and/or new routines (including the development routines).

It is essential to distinguish between these two types of activities, since knowledge externalities have quite different effects in the two cases. Both ordinary production activities and development activities involve interaction with other economic agents - interactions that give rise to interaction costs, which increase with geographical distance between the actual economic agents, and which are non-linear with regard to geographical distance. Hence, proximity brings an advantage to economic agents.

\section{I Economic nature of knowledge externalities}

As regards the economic nature of knowledge externalities, we have

- pecuniary knowledge externalities that operate via prices, i.e. via market links (intramarket knowledge externalities) or via inter-organization links (quasi-market knowledge externalities), which we may term connected knowledge spillovers, and 
- non-pecuniary (technological) knowledge externalities, which operate outside the market, i.e., extra-market knowledge externalities or if we like pure knowledge spillovers.

In perfect markets, there are no contacts between economic agents. In principle, they do not know each other. Some markets are rather close to perfect markets. However, different forms of links between economic agents characterize many markets. A suitable starting point for understanding such markets is the micro-level of individual decision-making units. The decision-making unit can be an economic agent in the form of a firm or other organization or household or individual decision-makers within firms and other organizations. A basic presumption here is that firms and other organizations have internal networks for communication and coordination of production and development activities. Certain internal networks consist of links that are arranged for the flow of resources, while other internal networks function as channels for diffusion and exchange of information and knowledge. All internal networks are connected and governed in such a way that economic agents are coherent.

Attached to the internal networks of economic agents are links that extend beyond the boundaries of the economic agent. Such links connect various economic agents with each other and constitute what we can call inter-organizational networks, which are used for flows of goods, services and/or knowledge. Interaction in this kind of knowledge networks can lead to the development of hybrid forms of knowledge that are freely available only to the network members and thus neither public nor private in character. This hybrid knowledge becomes a kind of club good for the network members (cf. Buchanan, 1965). Interaction between economic agents is based upon a formal or informal contract, which normally is long-term if one or several of the economic agents involved must make investments that are transaction- or link-specific.

\subsection{Sources of knowledge externalities}

New knowledge is generated by economic agents through deliberate search for new knowledge in the form of R\&D activities, and trough learning-by-doing, when carrying through different activities. This search is directed towards different kinds of sources. The sources can be classified into two groups: i) sources containing embodied knowledge including individuals, economic agents and products, and ii) sources containing disembodied knowledge, including books, articles, research and consultancy reports, patents, web pages. Since the knowledge generating activities are localised, regional knowledge externalities have two main spatial sources: i) intra-regional knowledge sources, i.e. knowledge sources characterized by geographical proximity, which lower the transaction costs and facilitates pure knowledge spillovers, and ii) inter-regional knowledge sources, i.e. knowledge sources in other regions, available via different interregional links. Proximity implies that transactions and planned interactions between economic agents become less costly and that the probability for non-planned interactions increases. More advanced types of interactions between economic agents are dependent upon trust and proximity makes it easier to develop trust (Breschi \& Lissoni, 2001).

However, for proximity to be important it must be proximity to something, in this case other economic agents with the relevant knowledge. One type of proximity is proximity to economic agents engaged in the same trade. Such clustering or co-location gives rise to a special form of agglomeration economies, namely localization economies, where specialization is an important feature. Clustering or co-location of economic agents from different trades gives rise to another type of agglomeration economies, namely urbanization economies, where diversity and size are essential features. Agglomeration implies that economic agents can bene- 
fit from mutual proximity but whether a more specialised or a more diversified regional economic milieu is most favourable for existence and size of localised knowledge spillovers is still an open question. It is in this connection important to observe that knowledge generation activities are more highly agglomerated than most other types of economic activities.

Anyhow, even if proximity is no guarantee for knowledge spillovers between economic agents, it has two important potential effects. It affects both how economic agents can interact in the market place and how they can interact outside the market place and benefit from nonpecuniary knowledge spillovers. Thus, proximity influences intra-market, and quasi-market as well as extra-market externalities. However, quasi-market externalities are different, since they represent a link between economic agents. Establishing a link to another economic agent is a means to reduce geographical interaction costs and thus to make proximity less critical, i.e. links can function as a substitute for proximity. However, since the establishment of an economic link involves search and negotiation costs, we must consider that link formation within a region can be less costly than formation of a link to an economic agent in another region, which implies that proximity play a role for extra-market externalities also.

\subsection{The recipients of knowledge externalities}

Knowledge spillovers across economic agents occur when the knowledge generated by one economic agent is 'borrowed' by other economic agents. Here, we must distinguish between spillovers between economic agents in the same trade and spillovers between economic agents in different trades (Audretsch \& Feldman 1999). One critical question here concerns whether the specific mix of economic activities undertaken within different regions matter for the extent and direction of knowledge spillovers, i.e., do knowledge spillovers occur mainly within or between trades? This question, which concerns the recipients of knowledge spillovers, is very relevant and a debate among researchers during the two last decades has focused precisely on how the knowledge externalities generated by knowledge spillovers are affected by the regional mix of economic activities. Despite a consensus that knowledge spillovers within a given region stimulate dynamic knowledge externalities, there is no agreement concerning which the recipients of these knowledge spillovers are.

Glaeser, et al. (1992), which analyses the factors that influence innovative activities in urban regions, illustrates the controversy. The authors identify two relevant models in the economics literature. The first model is the so-called Marshall-Arrow-Romer (MAR) model, which formalises the insight that the concentration of a particular trade within a specific urban region (Lösch, 1954) promotes intra-regional knowledge spillovers across economic agents in that particular trade and therefore stimulates innovation in that particular industry. The basic assumption here is that knowledge spillovers, and thus knowledge externalities, mainly takes place across economic agents in the same trade.

The alternative view regards inter-trade knowledge spillovers as the most important channel to diffuse new economically relevant knowledge. Not least, Jacobs (1969) argues that the agglomeration of economic agents from different trades in urban regions fosters innovations due to the diversity of knowledge sources located in such regions. The recipients of knowledge spillovers from economic agents in one particular trade are here economic agents in other trades. The assumption here is that the variety of industries within an urban region can be a powerful engine of growth for that region, and that the exchange of complementary knowledge across diverse economic agents leads to increasing returns to new knowledge. 
The empirical studies in the field give no clear answer to the question whether MAR or Jacobs's externalities are most important.

What must be observed is that the gains from knowledge spillovers do not apply uniformly across the economic agents in a region due to the heterogeneity among economic agents. They differ in terms of their history, age, size, knowledge and other resources, location, networks, ownership structure, routines, strategies and behaviour even if they belong to the same industry.

\subsection{Mechanisms of knowledge externalities}

Breschi \& Lissoni (2001) argue that it is important to improve the understanding of the knowledge transmission mechanisms in addition to study knowledge spillovers by a rather limited set of variables. The mechanisms conveying knowledge externalities include i) formal and informal interaction between economic agents, where the formal interaction is based on an explicit contract, while the informal interaction is based upon an implicit contract, ii) active knowledge search of economic agents, and iii) mobility of economic agents.

The formal and informal interaction between economic agents can take many forms ranging from transactions of goods and services including R\&D services to cooperation in the form of joint ventures and strategic alliances including $R \& D$ cooperation. It includes the interaction of employees of different economic agents privately and in social, civic and professional organizations. Since much knowledge is embodied in people, it is natural to assume that knowledge spillovers are partly a function of the interaction between people with the relevant education, skills and experiences. Relations to suppliers and/or customers are also potential channels for knowledge spillovers. Furthermore, trade with goods and services embodying knowledge is a further channel for knowledge spillovers and externalities (Grossman \& Helpman, 1991 b). Lastly, we have public policy programmes supporting the cooperation between economic agents, which can be potentially important channel for knowledge spillovers.

Active knowledge search involves what can be described as "business intelligence" and involves activities ranging from analyses of patent applications and academic publications to "reverse engineering" of products. Mobility of economic agents involves the mobility of labour as well as the mobility of firms and other organizations. The mobility of people between economic agents and between regions is a potentially important channel for knowledge spillovers. We may observe that there exist several more mechanisms, which support and facilitate the transfer and diffusion of tacit as well as codified knowledge and technology. They include i) education, ii) seminars, conferences and trade fairs, iii) interactive communication channels (E-mail, the Internet, video conferences, etc.), iv) people specially designated to obtain and disseminate knowledge (e.g. gatekeepers), v) knowledge management within and between economic agents, and vi) imitation.

It is important to notice that even if each of these channels or mechanisms can be seen as partly independent of each other, they are often linked to each other in different ways. It is in this connection important to observe that international cooperation in both the private and the public sector play an important role for knowledge diffusion. An increasing number of partnerships among firms, universities and public research centres as well as between individual researchers and inventors is a clear indication of the growing importance of collaboration. Collaboration permits the partners to share and acquire the expertise of each other, thus enriching their overall know-how. It often functions as a positive sum game, where the advan- 
tages outweigh the disadvantages even if the advantages are not always equally shared among the partners.

We are now in a position where we can disentangle the mechanisms behind intra-market, quasi-market and extra-market knowledge externalities. Starting with the intra-market knowledge externalities it is obvious that location and urbanization economies will make it possible for economic agents to buy inputs embodying knowledge with lower transaction costs and potentially also at a lower price due to proximity. We can here think of hardware as well as software embodying knowledge but we can also think of knowledge-intensive business services as relevant here. In particular, we can here think of purchases that are made ad hoc or so seldom that it is not rational to invest in a link. Urbanization economies bring diversity as an extra dimension, which gives economic agents an opportunity to test different suppliers with a somewhat different knowledge base for the same type of basic delivery and generate what is known as Jacobs's externalities (Jacobs, 1969). Localization and urbanization economies also make it possible for economic agents to sell knowledge-intensive outputs with lower transaction costs and potentially at a lower price due to proximity.

Quasi-market or transaction-link knowledge externalities represent idiosyncratic relations between economic agents that provide the participants with advantages that occur in a quasimarket setting besides the ordinary market, i.e. these knowledge externalities are a kind of club good. A link between economic agents for the delivery of knowledge or knowledge-intensive goods and/or services reduces transaction costs.

Extra-market knowledge externalities concern information and knowledge spillovers that occur as by-products in the course of all types of interactions between economic agents but can also occur without any direct interaction between economic agents. The prime focus here is on research, development and innovation activities that are assumed to be stimulated by such spillovers (Karlsson \& Manduchi, 2001).

However, we must also acknowledge that knowledge can spillover between economic agents without any direct interaction. Obvious examples are, when economic agents analyse patent applications and academic publications to get inputs, in particular, to their own research, development and innovation activities.

\subsection{The geographic reach of knowledge externalities}

A critical issue in analysing the role of knowledge spillovers and thus knowledge externalities for regional economic development is the geographic or spatial reach of knowledge spillovers. We have many reasons to believe that knowledge is subject to spatial decay. Due to "the tyranny of distance", most human interaction takes place within the functional region and in particular the locality where people live and often work. The claim that geographical proximity matters for knowledge spillovers between economic agents is largely supported by the empirical literature (Karlsson \& Manduchi, 2001). Already Glaeser, et al. (1992, 1127) maintain that spatial proximity facilitates knowledge spillovers, because "intellectual breakthroughs must cross hallways and streets more easily than oceans and continents". This is followed up by Audretsch \& Feldman $(1999,410)$ who argue, "knowledge spillovers not only generate externalities, but the evidence suggest that such knowledge spillovers tend to be geographically bounded". 
The statement by Audretsch \& Feldman that knowledge spillovers 'tend to be' geographically bounded indicates that knowledge spillovers also may occur between regions. Actually, the authors themselves only five years later argued "there is no reason that knowledge stop spilling over just because of borders, such as a city limit, state limit or national boundary" (Audretsch \& Feldman, 2004, 6). In this connection, it may be relevant to go back to Palander (1935), who observed that one of the most remarkable features of modern urban structures is the frequency and extension of the interactions between activities carried out in different cities. These interactions presuppose of course the possibility of communicating between cities. Possibilities that have multiplied many times since the 1930s due to, on the one hand, a telecommunications revolution that has lowered the marginal cost of information exchange between different locations to levels very close to zero, and, on the other hand, the evolution of highway and air travel networks that significantly has reduced the travel costs and the travel times. Thus, the interregional interaction costs have been reduced substantially in recent decades creating the necessary foundations for a global knowledge-intensive network economy. Against this background, we may ask to what extent it actually is true that interregional knowledge spillovers are limited in scope and spatial reach.

If we first turn our intention to scientific knowledge, we can indeed claim that the interregional knowledge spillovers are both substantial and rapid between individuals with the relevant absorptive capacity. The reason for this is that the international scientific community is organised in big knowledge networks, relying, for example, on international scientific conferences and journals and that rapid publication of new scientific results are important for the prestige of the individual scientists. Is technological knowledge then different? To a certain extent it is, since the economic agent that developed new technological knowledge normally does not want to share it without compensation with competitors. On the other hand, the economic agent who has been able to develop an innovation based upon own-developed new technology is eager that it should be diffused rapidly among customers wherever they are located before any competitor imitates the innovation. Entrepreneurship knowledge in the form of business ideas probably diffuses between regions without major problems, since it normally is not proprietary, even if trademarks and logotypes can be protected. Thus, it might be the case that the claims that geographical knowledge spillovers tend to be geographically bounded underestimates the geographical reach of knowledge spillovers. Actually, there is abundant evidence that the information and knowledge networks that enhance the efficiency and innovativeness of economic agents can be and often are widely diffused geographically. However, we need to stress that a critical factor that we do not discuss here is the speed with which that knowledge diffuses between regions.

\subsection{Consequences of knowledge externalities}

The consequences of knowledge externalities appear in the following forms:

- Efficiency externalities, which generate static differences between regions with regard to productivity and unit costs of economic agents, and

- Innovation externalities, which are dynamic phenomena and appear as new knowledge inducing changing economic efficiency (new routines) but also in the form of new products, increased product characteristic diversity and similar novelties.

We may assume that intra-market knowledge externalities and thus proximity is of special importance for efficiency externalities (cf., Johansson, 2005). However, we must observe that links, i.e. quasi-market externalities can function as an alternative to proximity. 
However, the focus here is mainly on innovation externalities. In recent decades, we have witnessed a substantial progress in the understanding of innovation processes both with regard to process and product innovations. In particular, this is true for the macro level, with the development of the endogenous growth models (Romer, 1986; Lucas, 1988). In these models, development of technology is an endogenous part of each model, and this endogeniety is coupled to assumptions about knowledge externalities.

Unfortunately, we must admit that the micro foundations for understanding innovation processes are less well developed. The micro oriented research on innovation processes has had a much stronger empirical focus and has partly been centred on concepts such as regional innovation systems and innovative milieu.

\section{Knowledge externalities and regional economic development}

In this section, we turn our focus to the effects of knowledge externalities on regional economic development. How does knowledge flows generally influence regional economic development? Orthodox economic theory gives two answers:

i) Knowledge affects regional economic development via the production functions of regional economic agents by improving their use of their inputs, i.e. their productivity (Chambers, 1988).

ii) Knowledge affects regional economic development via the value ladder of product varieties produced by regional economic agents (Grossman \& Helpman, 1991 a).

However, orthodox economic theory says nothing about the knowledge generation and diffusion mechanisms in general and knowledge spillovers in particular. A natural starting point for an increased understanding of these issues is a simple endogenous regional growth model for an isolated region, since concepts related to knowledge generation, knowledge accumulation, knowledge appropriation, knowledge flows and knowledge spillovers are prominent features of such models as well as in the literature on innovation systems (Lundvall, 1995, Ed.). These models also provide a systematic approach to the understanding the adaptive capacity of a regional economy. Endogenous growth models describe the growth process of the isolated region and suggest that continuous increases in knowledge ("technology") due to investments in knowledge generation increase aggregated economic growth in the region (cf. Romer, 1986 \& 1990). The basic idea behind such models is that part of a region's resources is used to produce an output that can be used for consumption and investment, while the remaining resources are employed in producing new knowledge ("technology"). Since knowledge is treated as non-rivalrous and only partially excludable, these models exhibit increasing returns. However, imperfect competition is needed for R\&D investments to be worthwhile for economic agents. The innovations generated through the R\&D investments later become the intermediate inputs for other firms, and hence the rate of innovation determines the overall rate of growth.

New (technological) knowledge is in this kind of models used in two ways in the regional economy:

i) The economic agent in the region that developed it uses new knowledge in the production of a specific unique product. Other economic agents in the region are excluded from using the same knowledge by means of patenting. 
ii) New knowledge increases the total stock of knowledge in the region but may spill over to other economic agents to be used in knowledge production by means of examination of patent documentation (Romer, 1990). Thus, the knowledge production productivity in the region increases. It may very well be that the new knowledge benefits other economic agents as much or even more than the economic agent, that created it.

One limiting factor of this original Romer-approach is the assumption of general accessibility of the stock of knowledge in general and new knowledge in particular for all economic agents in the region. There are strong reasons to believe that in particular new knowledge is not evenly accessible for economic agents in a region, since for example, not all new knowledge is patented but instead kept as business secret and not all economic agents have the absorption capacity necessary to use the new knowledge. Another limiting factor is that knowledge is treated as a homogenous concept and that no distinction is made between different types of knowledge.

Due to their aggregated character, these models have limitations when it comes to understanding the relation between knowledge production and economic growth at different levels of identification: the level of economic agents, the level of industries and the regional level. Knowledge is assumed to spillover between economic agents in the region and to generate knowledge externalities but the precise mechanisms are not explicated.

Another problem with the single-region Romer-model is the separation from all other regions. Economic agents trade with economic agents in other regions and economic agents make direct investments in other regions. Furthermore, people travel and move between regions, so there are numerous mechanisms through which knowledge will diffuse from one region to another, and have impact upon productivity and innovation and thus regional economic development in other regions.

An alternative type of endogenous growth model is the intentional human capital model, which stresses the critical importance of education, learning-by-doing and knowledge spillovers. Technological progress is here the result of intentional research and education investments and here human capital is an element in the aggregate production function. Here, investments in human capital generate knowledge spillovers, which increase the productivity of both physical capital and the general labour force.

Moving from a single-region to a multi-region framework leads to a number of complications, when we want to disentangle the extent to which that knowledge externalities influence regional economic development. We must acknowledge

- that regions are different not least in terms of agglomeration, industrial structure, and accessibility to and interaction with other regions,

- that regional economic development is path-dependent, i.e., history matters,

- that the capacity to adapt to economic, technological and institutional changes varies between regions,

- that self-organization prevails due to the actions of households and economic agents,

- that knowledge and knowledge generation is not evenly dispersed, but instead unevenly distributed and in particular concentrated in (large) cities, and

- that the distribution pattern differs for different types of knowledge and institutions. 
Thus, the development potential of different regions is dependent upon their historical development paths including the partly self-organised (dis-)accumulation of infrastructure, economic agents, knowledge and institutions and the pertinent potential for intra- and inter-regional knowledge spillovers, which defines the potential development trajectory for each region. Certainly, those regions that offer larger knowledge and other externalities have ceteris paribus a larger development potential than other regions. The drivers behind regional economic development is the initiation of new technologies, new product cycles, new industries, new infrastructures and new institutions that over time complements or replaces old ones through processes with different speeds. Hence, the economic development in different regions hinges on their capacity to absorb, generate and adapt knowledge and to generate and nurture such novelties. This capacity is given our discussion above dependent upon i) the education level of the regional labour force and the incentives for individuals to participate in education, ii) the incentives for economic agents to undertake $R \& D$ and to innovate, and iii) the degree to which knowledge diffuses within the region and from other regions.

Endogenous growth models tell us that the regions that are most well-equipped with resources are most likely to accumulate more resources and increase productivity more over time according to the principle of circular and cumulative causation (Myrdal, 1957). However, this form of positive feedbacks is in general constrained, on the one hand, by the development of the demand of the region and its external markets, and, on the other hand, by the existing capacities in the form of built environment, accessibility-based transport systems, production capacities, and labour supply. Anyhow, differences between regions may "accrue from the growth of industry itself - the development of skill and know-how; the opportunities for easy communication of ideas and experience; the opportunity of ever-increasing differentiation and of specialisation in human activities" (Kaldor, 1970, 340).

It is certainly beyond the purpose of this paper to present a formal multi-regional model that in a consistent manner integrates the effects of knowledge flows and pertinent knowledge spillovers on regional economic development. The discussion here is limited to a discussion of some of the factors that must be considered when modelling knowledge-based multi-regional growth. We start with discussing new economic geography models and knowledgebased regional growth. Then we continue with discussing first the role of interregional knowledge on multi-regional growth, and second how knowledge flows influence the behaviour of individual economic agents. New economic geography models combine economies of scale with reduced transport costs to explain why similar economic activities will tend to concentrate in the same locations. These locations will become densely populated and will have higher levels of income (Krugman, 1991).

\section{I New economic geography models and knowledge-based regional growth}

It is well known that the original new economic geography models are not suitable to model the role of knowledge spillovers and knowledge externalities in regional economic growth because Krugman originally refused to model technological externalities (Krugman, 1991). However, the literature on innovation systems convincingly shows that

- knowledge generation is highly geographically concentrated, and thus that regions differ substantially in their volume of knowledge production, 
- regions differ substantially in terms of absorption capacity and accessibility to external knowledge, and

- its own unique knowledge mix characterizes each region.

It also stresses that knowledge flows and pertinent knowledge spillovers are at the core of knowledge-based regional development. This implies that the location of knowledge generation and the structure of the spatial networks for knowledge flows and knowledge spillovers are fundamental factors in modelling knowledge-based regional economic development. In addition, it must be acknowledged that the potential of economic agents to absorb new scientific, technological and entrepreneurial knowledge is facilitated by geographic proximity (Jaffe, Trajtenberg \& Henderson, 1993). The exchange of knowledge and ideas may generate such technological externalities that it influences the location decisions of economic agents, and induces them to cluster at specific locations (Marshall, 1920) generating differences in income and productivity across geographic space (Henderson, 1974). It was first with the merger of new economic geography models and endogenous growth models that knowledge spillovers were taken into account in the new economic geography literature. The critical message here is that when human capital and other capital resources, including R\&D competence, are located together in the same region, self-reinforcing processes can be obtained, i.e., such concentrations have the power to further stimulate economic growth in these regions.

Large (and dense) regions offer special advantages in terms of knowledge flows and potential for knowledge spillovers, since they normally host research universities, private R\&D facilities and many industrial clusters, i.e. industrial diversity. Small (and sparsely populated) regions on the other hand are normally characterised by a lack of research universities and private $\mathrm{R} \& \mathrm{D}$ facilities as well as by having only one or a few industrial clusters or being dependent upon large scale industries. This suggests the possibility of formulating a model along the lines of new economic geography principles, which takes one of its starting points the favourable conditions for knowledge generation and large potential for knowledge flows and knowledge spillovers in large regions. When such a region for any reason has achieved an initial advantage in knowledge generation, it will attract knowledge-generating and knowledge-utilizing economic agents, since it offers opportunities to get advantages in terms of increasing returns in knowledge-generation and knowledge-utilization.

Although it is indeed true, that it is economic agents and not regions that compete, there are important regional production and knowledge advantages being pursued by the many economic actors within large regions. This leads to an important premise about scientific, technological and entrepreneurial knowledge and innovations in large regions. New knowledge and innovations emerge uniquely out of large regions not simply because one or the other was endowed with a certain initial stock of knowledge and factors of production, but because many assets necessary for knowledge generation and innovations are created in the course of the on-going knowledge generation, innovation and production activities among economic agents. These assets include new scientific, technological and entrepreneurial knowledge, which are prerequisites for novelty-by-combination processes, which generate new knowledge and innovations but which facilitate the exploitation of knowledge resources and the development of regional formal and informal institutional innovations to support and sustain intra-regional knowledge flows. Furthermore, many of these scientific, technological, entrepreneurial and institutional assets are not easily transferrable between regions and thus may preserve regional advantages for a long time. 
The size of the regional market potential influences the probability that new knowledge in the form of inventions is turned into innovations in the region. The underlying reason is that a large market potential generally increases the demand for knowledge-intensive products. The probability that inventions are turned into innovations increases with the size of the regional market potential, and this gives knowledge-creating and knowledge-utilizing economic agents an extra advantage of locating in large regions. In addition, when more of these economic agents locate in large regions, this makes these regions more attractive for knowledge workers, which fuels the cumulative process and makes the region still more attractive for knowledge-intensive economic agents. More knowledge handlers and more knowledge-intensive economic agents in a region increase its market potential and make it still more attractive. Thus, we may conclude that from an endogenous growth perspective, that regions that have a first mover advantage in terms of knowledge, technology and innovation are likely to attract educated labour (and capital) from other regions and thereby generating a cumulative selfreinforcing process of $R \& D$ and innovation leadership. This implies that the scarce and critical resources in knowledge-based regions are factors such as highly educated labour, education system, R\&D system, knowledge flows and spillovers and innovation capability.

When large innovative regions grow, the demand for land, premises and labour increases, which tend to drive up their prices. However, these price increases are a necessary mechanism to secure that resources gradually are pressed out of maturing industries, and made available for new growth industries. This implies that economic growth in large innovative regions is strongly related to the functioning of the relevant markets. Of course, a condition for longterm growth is that the advantages in terms of knowledge and other spillovers increases with at least the same speed as the agglomeration costs.

\subsection{Interregional knowledge flows and multiregional growth}

The discussion in this section builds upon an endogenous growth model introduced by Andersson and Mantsinen (1980). The model is centred on a production function for each region $r, Q_{r}=Q\left(K_{r}, A_{r}\right)$, where $K_{r}$ represents the total production capital in region $r$ and $A_{r}$ the total accessible knowledge in region $r$. The knowledge resources in any region $r$ are $G_{r}$, but region $r$ can also benefit from knowledge resources in all other regions $s, G_{s}$. Thus, $A_{r}$ represents a compound knowledge consisting of knowledge within region $r$ and accessible knowledge in other regions.

With the help of the above model components, it is possible in a stylized way to illustrate how regional and interregional knowledge resources influence regional economic growth. $G$ represents here all types of knowledge as well as the capacity to develop new knowledge. Now assume that knowledge can be treated as a spatial public good, such that $G_{s}$ in any region $s$ influences the accessible knowledge in region $r$ via a distance-decay factor $f_{s r}=\exp \left\{-\lambda t_{s r}\right\}$, where $\lambda$ is the travel time sensitivity and $t_{s r}$ is the travel time distance between region $r$ and region $s$. This implies that

$$
A_{r}=\sum_{s} f_{s r} G_{s}
$$

summarizing the total accessible knowledge in region $r$, where $f_{r r}>f_{s r}>0$, for $s \neq r$. In this model, the accessible knowledge will change when any of the $G$-varibles, travel sensitivities and/or travel time distances change. Changes in the $G$-varibles are the outcomes of knowledge generation processes, which can be illustrated by the following differential equation: 


$$
\dot{G}_{r}=H\left[g_{r}\left(A_{r}\right), \tau_{r}\left(Q_{r}\right), \theta_{r}\left(Q_{r}\right)\right]
$$

where $g_{r}$ is the R\&D productivity in region $r$, which is a function of accessible knowledge in region $r, A_{r}, \tau_{r}$ is the share of output $Q_{r}$ devoted to $\mathrm{R} \& \mathrm{D}$ in region $r$ and $\theta_{r}$ is the "learning by doing productivity" in region $r$, which is a function of total output in region $r$. The important message here is that regions do not only rely of their own internal knowledge and capacity to generate knowledge but also on their capacity to integrate knowledge generated in other regions. If we also introduce a second dynamic equation that describes the accumulation of production capital in region $r, K_{r}$, we get a simple model of multi-regional development:

$$
\dot{K}_{r}=s_{r}\left(1-\tau_{r}\right) Q_{r}
$$

where $s_{r}$ signifies the investment coefficient in region $r$. We will not here discuss the equilibrium properties of this model. Instead, we limit our comments here to aspects of knowledge generation and knowledge flows.

We start with discussing the knowledge generation process in a region $r, \dot{G}_{r}$. It seems reasonable to assume that large and rich (and dense) regions will have advantages in terms of knowledge generation. They have a large output, can afford to devote large resources to $R \& D$, have a larger capacity for learning-by-doing due to a larger output and have normally larger knowledge accessibility due to a large intra-regional knowledge pool and a good accessibility to other large regions with a large knowledge pool.

What then can we say about knowledge flows and the potential for knowledge spillovers? It is obvious that the knowledge accessibility of a region is critical here. Regions with a high accessibility to knowledge-rich regions obviously have a higher potential for knowledge flows and pertinent knowledge spillovers. A high accessibility does not only imply a high probability for trade flows but also for direct investments and for interaction between people. These are all mechanisms that can generate knowledge spillovers and thus be a source for increasing returns in regional economic development.

\subsection{Microeconomic aspects of knowledge spillovers, knowledge externalities and regional economic development}

Aggregated regional growth models offer general understanding of some of the basic factors that drive regional economic development. These models illustrate the importance of R\&D, human capital investments, endogenous technological change, exports, agglomeration economies and knowledge and other spillovers from a theoretical perspective but they are too aggregated for empirical testing. This implies that these models do not have enough capacity to discriminate between different factors in terms of their importance for regional productivity and general regional economic growth. These models also have problems in identifying, which the true exogenous factors are, i.e. the factors that are of interest for regional policymaking.

Another problem with the aggregated models is that they assume that all economic agents are homogenous in all respects. Thus, these models fail to acknowledge that economic agents are heterogeneous in terms of their history, age, size, knowledge and other resources, location, networks, ownership structure, routines, strategies and behaviour even if they belong to the same industry. Industrial and regional productivity growth and general economic growth is 
generated by a large number of different individual processes within the different economic agents, which are influenced by different internal and external. In every industry, there are economic agents that are persistently investing in $\mathrm{R} \& \mathrm{D}$, while other economic agents invest now and then or not at all. The same is true for exports and imports. In terms of efficiency, we know that productivity distributions are characterised by a high degree of inertia, and that the position that the different economic agents occupy in the distribution is highly persistent over time.

To overcome these deficiencies and to increase our understanding of how knowledge spillovers and knowledge externalities influence regional economic development, we need a model framework at the micro-economic level capable of accommodating different conditions and different behaviour among economic agents within the same industry. Thus, we need a model framework able of analysing the factors influencing the behaviour of different economic agents as well as the effects of differing behaviour among economic agents in terms of productivity improvements and increased market shares. It is beyond the scope of this chapter to develop such a microeconomic framework with such a capability. However, in the sequel we highlight some aspects that are critical for developing such a framework.

An externality in production emerges when the output from one economic agent is influenced not only by its own inputs but also from the outputs and inputs used by other economic agents. When the externality emerges within the region, where the economic agent is located, it has the character of a proximity externality. We talk about localization economies, if other economic agents in the same trade generate the externality. If economic agents in other trades generate the externality, we talk about urbanization economies. If the externality emerges from outside the region, we can talk about an extra-market or network externality. Assuming that economic agents are engaged in two types of production - the production of goods and services and the production of knowledge - we can formulate two functions that describe the two processes, the first being the production function for economic agent $i$, in industry $j$ in region $r$ :

$$
q_{i, j, r}=A_{i, j, r}\left(c_{i, j, r}^{q}\right) f\left(x_{i, j, r}, y_{j, r}, z_{n, r}, E_{s}\right)
$$

where $q$ signifies output, $A_{i, j, r}$ the accessible knowledge for economic agent $i, c_{i, j, r}^{q}$ is the absorptive capacity of economic agent $i$ of production relevant knowledge, $x_{i, j, r}$ the inputs used by economic agent $i, y_{j, r}$ the accessibility to other economic agents in the region in the same trade as economic agent $i, z_{n, r}$ the accessibility to other economic agents in the region in other trade than $i, E_{s}$, the accessibility to economic agents in all other regions $s$. The above formulation implies that the productivity level in the economic agent $i$ depend on its knowledge level, the size of the localization economies, the size of the urbanisation economies and the size of the extra-market externalities. What about then the generation of knowledge by economic agent $r$ ? Knowledge generation by economic agent $i$, in trade $j$ in region $r$ is

$$
\dot{g}_{i, j, r}=h\left\{g_{i, j, r}\left[A_{i, j, r}, \dot{g}_{j, r}^{A}, \dot{g}_{n, r}^{A}, \dot{g}_{s}^{A}, \theta_{i, j, r}\left(q_{i, j, r}\right), c_{i, j, r}^{g}\right], \tau_{i, j, r}\left(q_{i, j, r}\right)\right\}
$$

where $g_{i, j, r}$ is the research productivity by economic agent $i, \dot{g}_{j, r}^{A}$ is the accessibility to knowledge output from other economic agents in trade $j$ in region $r, \dot{g}_{n, r}^{A}$ is the accessibility to knowledge output in other trades in region $r, \dot{g}_{s}^{A}$ is the accessibility to knowledge output in other regions, $\theta_{i, j, r}$ is the "learning-by-doing productivity" in economic agent $i, c_{i, j, r}^{g}$ is the 
absorptive capacity of economic agent $i$ of R\&D-relevant knowledge, and $\tau_{i, j, r}$ is the share of the output from economic agent $i$ devoted to $R \& D$. The current formulation tells us that an economic agent combines its current knowledge with new knowledge developed by economic agents in the same trade and in other trades in the home region, new knowledge developed in other regions and with knowledge gained from the own production experience. The three knowledge accessibilities included represent three potentials for knowledge flows and thus for knowledge spillovers. However, the probability of each economic agent to succeed in the knowledge generation game is among other things dependent upon their skills and capacity in interacting with other economic agents, including, for example, research universities, in the home region as well as in other regions. It is also dependent upon the extent to which the location offers suitable interaction infrastructures and meeting places and formal and informal institutions including both a potential to protect the newly generated knowledge, and the necessary level of trust for successful interaction between economic agents. The formulation allows for intra-market, quasi-market and extra-market spillovers in line with the earlier discussion in this chapter. Concerning the extra-market spillovers, we want in particular stress the role that exports and imports play as potential channels for knowledge spillovers. These spillovers can be direct but they might also be indirect coming via other exporting or importing firms in the region.

The framework illustrated above is only a very partial framework. One important aspect missing is the creative destruction along Schumpeterian lines, i.e. the scale and causes of entry and exit of economic agents and the role of knowledge spillovers in this respect. Innovation may represent a vehicle for new economic agents to enter the market successfully. However, since new firms by definition have done no R\&D of their own, spillovers of scientific, technological and entrepreneurial knowledge provide an explanation for innovative entry by new economic agents. Different regions have varying endowments of knowledge, and not least new knowledge, which implies that the potential for innovative entry differs between regions and that larger regions generally offer a higher potential since they also offer a larger market potential. Of course, individuals and groups of individuals differ in their capacity to discover, create and exploit innovations, i.e. to create new combinations, but since individuals in larger regions generally have a higher education, more varied work experiences and more extensive personal networks these regions have an advantage here too.

\section{Knowledge externalities and regional economic development: policy conclusions}

Regional economic development seems increasingly to be dependent upon internal network structures to exploit fully the internal knowledge base, while at the same time absorbing new knowledge from outside the region. Given the potentially large importance of knowledge spillovers for regional (and thus national) economic development, policy makers have strong incentives to partly shift their traditional focus on the share of GRP and GDP invested in R\&D to measures that foster knowledge spillovers, intra-regional as well as inter-regional. Concerning stimuli to intra-regional knowledge spillovers, policymakers should first of all focus on increasing intra-regional accessibility by means of investments in transport infrastructure and public transport. It is also important to establish arenas and meeting places where economic agents in the region can meet and interact.

Even if one should not underestimate the importance of intra-regional knowledge spillovers, it seems in particular important to promote inter-regional knowledge spillovers. There are certainly many channels for inter-regional knowledge flows. Starting with academic channels, 
we claim that it is important to involve scientists from other regions and countries in advanced research programs and to encourage scientists to engage in inter-regional and international cooperation and co-authorships as well as being guest researchers at research universities and laboratories in other countries. With a rapidly increasing number of patents and academic publications, it becomes more and more important to support inventors in all fields with rapid updates on new patents and publications. In particular, small and medium-sized firms might need support when buying patents and licences from other regions as well as in finding the right consultants in other regions. A positive and supportive attitude to strategic R\&D cooperation with economic agents in other regions is also important. The role of imports of hightechnology and knowledge-intensive products for inter-regional and international knowledge flows is often neglected. For regions that want to maximise the potential for inter-regional knowledge spillovers, it is important to create good conditions for import activities, not least through a high inter-regional accessibility. The same is true for direct investments from other regions. Multinational firms play an important but probably underestimated role for inter-regional knowledge spillovers. Another important channel for inter-regional knowledge flows is the in-migration of highly educated and skilled labour. Not least is it important to create an institutional framework that makes it easy for in-migrants to find information about available jobs, to apply for jobs, to find housing, etc.

\section{Conclusions}

There exists today a large literature on knowledge flows mainly using the concept knowledge spillovers without often making any distinction between intended and non-intended knowledge flows. The literature is not clear of the relative role of intended, i.e. market based, versus non-intended, i.e. spillover, knowledge flows. This distinction is important, since it is only the latter type, which generates any knowledge externalities. The discussion of knowledge externalities in the literature has had a focus on technological spillovers but it is obvious that there also exist pecuniary knowledge externalities. Thus, there is a substantial confusion in the literature as regards the economic nature of knowledge externalities. A similar confusion concerns the sources of knowledge spillovers. Many empirical studies have analysed the role of patent citations but it is obvious that economic agents learn from many other sources but patents. Another controversy concerns who benefits from knowledge spillovers. Is it mainly economic agents in the same trade or is it mainly economic agents in other trades? In terms of the mechanisms and channels for knowledge spillovers, it is obvious that learning takes place through many channels but that most studies only consider one channel at a time. A hot topic is the spatial reach of knowledge spillovers. It is a common statement in the literature that knowledge spillovers are bounded in geographical space. However, this statement needs to be seriously questioned in the time of the Internet with global air connections, satellite TV channels, and a high volume of international trade, direct investments, travelling and labour mobility. Furthermore, the consequences of knowledge spillovers and knowledge externalities are not well understood, disentangled and analysed. This state-of-the-art certainly complicates analyses of the role of knowledge spillovers and knowledge externalities for regional economic development. A central problem here is that the majority of the studies are done at an aggregated level assuming that there is only one type of knowledge, and that all economic agents are equal and benefitting to the same extent from knowledge spillovers. This implies that researchers in the field today have all too little understanding to guide policymakers. What we need for the future is multi-level studies based upon microeconomic data for economic agents, who recognize that economic agents and regions are hetereogenous, that different economic agents use different types of knowledge, use different knowledge channels, differ in their absorptive capacity, etc. 


\section{References}

Andersson, Å.E. \& J. Mantsinen (1980), Mobility of Resources: Accessibility of Knowledge and Economic Growth, Behavioural Science 25, 353-366

Arrow, K.J. (1962), Economic Welfare and the Allocation of Resources for Invention, in Nelson, R. (Ed.), The Rate and Direction of Inventive Activity, Princeton University Press, Princeton, 619-622

Audretsch, D.B. \& M.P. Feldman (1999), Innovation in Cities: Science-Based Diversity, Specialization and Localised Competition, European Economic Review 43, 409-429

Audretsch, D.B. \& M.P. Feldman (2004), Knowledge Spillovers and the Geography of Innovation, in Henderson, J.V. \& J.F. Thisse (Eds.), Handbook of Urban and Regional Economics, Vol. 4, Elsevier, Amsterdam, 2713-2739

Breschi, S. \& F. Lissoni (2001), Localized Knowledge Spillovers vs. Innovative Milieux: Knowledge Tacitness Reconsidered, Papers in Regional Science 80, 255-273

Buchanan, J.M. (1965), An Economic Theory of Clubs, Economica 32, 1-14

Chambers, R.G. (1988), Applied Production Analysis: A Dual Approach, Cambridge University Press, Cambridge

Cohen, W.M. \& D.A. Levinthal (1989), Innovation and Learning: The Two Faces of R\&D, Economic Journal 99, 569-596

Cornes, R. \& T. Sandler (1986), The Theory of Externalities, Public Goods and Club Goods, Cambridge University Press, Cambridge

Glaeser, E.L., et al. (1992), Growth of Cities, Journal of Political Economy 100, 1126-1152

Griliches, Z. (1992), The Search for R\&D Spillovers, Scandinavian Journal of Economics 94 (Supplement 1992), 29-47

Grossman, G.M. \& E. Helpman (1991 a), Quality Ladders and Product Cycles, Quarterly Journal of Economics 106, 557-586

Grossman, G.M. \& E. Helpman (1991 b), Innovation and Growth in a Global Economy, The MIT Press, Cambridge, MA

Helpman, E. (2008) (Ed.), Institutions and Economic Performance, Harvard University Press, Cambridge, MA

Henderson, J.V. (1974), The Size and Type of Cities, American Economic Review 64, 640656

Jacobs, J. (1969), The Economy of Cities, Random House, New York

Jaffe, A. (1986), Technological Opportunities and Spillovers of R\&D: Evidence from Firm's Patents, Profits, and Market Value, American Economic Review 76, 984-1001

Jaffe, A. (1989), Real Effects of Academic Research, American Economic Review 79, 957970

Jaffe, A., M. Trajtenberg \& R. Henderson (1993), Geographic Localization of Knowledge Spillovers as Evidenced by Patent Citations, Quarterly Journal of Economics 108, 577598

Johansson, B. (2005), Parsing the Menagerie of Agglomeration and Network Externalities, in Karlsson, C., B. Johansson \& R.R. Stough (Eds.), Industrial Clusters and Inter-Firm Networks, Edward Elgar, Cheltenham, 107-147

Kaldor, N. (1970), The Case for Regional Policy, Scottish Journal of Political Economy 17, 337-348

Karlsson, C. \& A. Manduchi (2001), Knowledge Spillovers in a Spatial Context - A Critical Review and Assessment, in Fischer, M. \& J. Frölich (Eds.), Knowledge, Complexity and Innovation Systems, Springer, Heidelberg, 101-123

Krugman, P.R. (1991), Geography and Trade, Leuven University Press, Leuven

Lucas, R. Jr. (1988), On the Mechanisms of Economic Development, Journal of Monetary Economics 22, 3-42 
Lundvall, B.-Å. (1995) (Ed.), National Systems of Innovation - Towards a Theory of Innovation and Interactive Learning, Biddles, London

Lösch, A. (1954), The Economics of Location, Yale University Press, New Haven, CT

Marshall, A. (1920), Principles of Economics, $8^{\text {th }}$ Edition, Macmillan, London

Myrdal, G. (1957), Economic Theory and Underdeveloped Regions, Duckworth, London

Nelson, R.R. \& S. Winter (1982), An Evolutionary Theory of Economic Change, Harvard University Press, Cambridge, MA

Palander, T. (1935), Beiträge zur Standorttheorie, Almqvist \& Wicksell, Uppsala

Rogers, E.M. (1983), Diffusion of Innovations, 3 ed., The Free Press, New York

Romer, P. (1986), Increasing Returns and Long Run Growth, Journal of Political Economy 94, 1002-1037

Romer, P. (1990), Endogenous Technological Change, Journal of Political Economy 98, 71102 